\title{
Zinc-positive and zinc-negative connections of the claustrum
}

\author{
Kathleen S. Rockland ${ }^{1,2 *}$ \\ ${ }^{1}$ Department of Anatomy and Neurobiology, Boston University School Medicine, Boston, MA, USA \\ ${ }^{2}$ Cold Spring Harbor Laboratory, Cold Spring Harbor, NY, USA \\ *Correspondence: krock@bu.edu
}

Edited by:

Brian N. Mathur, University of Maryland School of Medicine, USA

Reviewed by:

Richard H. Dyck, University of Calgary, Canada

Keywords: amygdala, epilepsy, feedback, layer 1, reuniens

Three features often mentioned as characteristic of the claustrum are its widespread connections with cortical areas, the reciprocity of these connections in general, and the origin of cortico-claustral connections from a distinctive subtype of layer 6 pyramidal cells (Sherk, 1986; Katz, 1987; Tanne-Gariepy et al., 2002; Crick and Koch, 2005; Smythies et al., 2012). Another feature, often overlooked, is that a proportion of claustral-cortical neurons use synaptic zinc and that zinc+ terminations are moderately dense in the claustrum. This article will summarize data about zinc and the claustrum and present the case that cortico-claustral neurons might also be zinc-positive $(\mathrm{Zn}+)$. I conclude with comments on the likely implications for claustral identity and function.

\section{ZINC-CONTAINING NEURONS}

There are several excellent reviews on the importance of synaptic zinc in the central nervous system (Frederickson et al., 2000, 2005; Nakashima and Dyck, 2009; Sensi et al., 2009). In brief, $\mathrm{Zn}+$ neurons are predominantly in the cerebral cortex and amygdala. $\mathrm{Zn}+$ neurons (i.e., those in which zinc is highly concentrated in the synaptic vesicles) are a subset of glutamatergic neurons, exclusive of corticothalamic. The projections between thalamus and cortex are zinc-negative $(\mathrm{Zn}-)$. Zinc is considered an activity- and calciumdependent neuromodulator of excitation and as being important in synaptic plasticity. It interacts with a wide range of zincsensitive postsynaptic membrane targets (see Table 1 in Frederickson et al., 2005 and Figure 2 in Sensi et al., 2009). In general, $\mathrm{Zn}+$ neurons have been preferentially associated with limbic projections; and the hippocampal mossy fibers are well-known to have a high concentration of synaptic zinc.

The brainwide distribution of $\mathrm{Zn}+$ neurons is demonstrated by intraperitoneal injection of sodium selenite, which produces a zinc-selenium precipitate that is retrogradely transported from axon terminals to cell bodies of origin (e.g., Brown and Dyck, 2004). Focal intra-cerebral injections of sodium selenite are used to retrogradely label target-specific projection neurons. Terminations are visualized by modifications of the classic Timm stain.

\section{CLAUSTRAL-CORTICAL PROJECTIONS}

Zinc-selenium histochemistry reveals a subset of $\mathrm{Zn}+$ neurons in the mouse claustrum (Brown and Dyck, 2004); and focal injections of sodium selenite in different cortical areas in rodent directly demonstrate a subset of $\mathrm{Zn}+$ cortically projecting neurons in the claustrum. These are reported as sparse or moderate for projections, respectively, to visual and barrel cortex, but more abundant for those to frontal and orbital cortical areas (Garrett et al., 1992; Casanovas-Aquilar et al., 1998; Brown and Dyck, 2005). Experiments using standard retrograde tracers report a small proportion of double labeled neurons projecting to two different cortical areas (in rat: Li et al., 1986; in cat: Clasca et al., 1992). Whether these are $\mathrm{Zn}+$ or not is unknown.

The claustrum also sends projections to the amygydala (for monkey: Stefannacci and Amaral, 2000), to parts of the subicular complex (Witter et al., 1988; Zhang et al., 2013), and to nucleus reuniens (for rat: McKenna and Vertes, 2004). There are no data as to the proportion of claustral-amygdala or claustralhippocampal neurons that might be $\mathrm{Zn}+$; and claustral-thalamic projections can be assumed as $\mathrm{Zn}-$.

Claustral-cortical projections labeled with standard anterograde tracers terminate in layers 1-4 and 6 (Clasca et al., 1992; da Costa et al., 2010). This partially coincides with the pattern of $\mathrm{Zn}+$ terminations, which are elevated in layers $1 b, 2,3$, and $5 / 6$, depending on the cortical area. As layer 4 is relatively $\mathrm{Zn}-$, claustral-cortical terminations in this layer can be inferred to originate from a separate subset of $\mathrm{Zn}-$ neurons in the claustrum. The proportion of $\mathrm{Zn}+$ terminations may be taken to vary depending on the species and projection system. For claustral-cortical projections, an initial guess might be $25-50 \%$ as being $\mathrm{Zn}+$, largely based on the density of $\mathrm{Zn}+$ neurons retrogradely labeled in the claustrum following focal injections of sodium selenite in cortical areas in rodents.

By comparison, cortical feedback projections from monkey temporal cortex have been shown to consist of a mix of $\mathrm{Zn}+$ and $\mathrm{Zn}-$ components by cortical injections of sodium selenite. In confirmation, injections of the anterograde tracer BDA in area TE were coupled with a terminal intravenous injection of sodium sulfide to precipitate $\mathrm{Zn}+$ terminations. Subsequent ultrastructural inspection of BDA-labeled terminations in areas targeted by TE neurons (V1, V4, TEO, and the depth of the superior temporal sulcus) revealed about one-third of the synapses as $\mathrm{Zn}+$, except for a higher proportion in V1 (four of five identified synapses; 
Ichinohe et al., 2010). As a second comparison, projections from the basolateral amygdala to medial prefrontal cortex were all found to be $\mathrm{Zn}+$ in the monkey (Miyashita et al., 2007), although only $35 \%$ of the amygdalo-cortical terminations were $\mathrm{Zn}+$ in rats (Cunningham et al., 2007).

\section{CORTICO-CLAUSTRAL NEURONS}

Layer 6 contains a mixed population of pyramidal neurons, of which the four major groups are intrinsically projecting, and extrinsically projecting to the thalamus, to other cortical areas, and to the claustrum (Briggs, 2010; Thomson, 2010). Corticothalamic neurons are $\mathrm{Zn}-$; and feedback cortically projecting neurons in layer 6 are intermixed $\mathrm{Zn}+$ and $\mathrm{Zn}-$ (for monkey: Ichinohe et al., 2010). There have been no appropriate injections in the claustrum to determine directly whether any cortico-claustral projecting neurons are $\mathrm{Zn+}$, but this possibility is supported by indirect evidence, as discussed next.

First, as noted above, $\mathrm{Zn}+$ terminations are moderately dense in the claustrum (rat: Perez-Clausell, 1996; Valente et al., 2002; monkey: Figure 1 in Ichinohe and Rockland, 2005a; Figure 10 in Miyashita et al., 2007). Zn+ cortico-claustral neurons are one of three possible sources of the $\mathrm{Zn}+$ terminations in the claustrum. Another is the claustrum itself, since it has both $\mathrm{Zn}+$ neurons (Brown and Dyck, 2004) and widespread intrinsic connections (Smith and Alloway, 2010). The amygdala is a third possible source. Several claustral projecting subnuclei in the amygdala contain $\mathrm{Zn}+$ neurons, demonstrated by intraperitoneal (Brown and Dyck, 2004) or focal injections of sodium selenite in cortical areas (for the rat: Majak et al., 2002; for monkey: Ichinohe and Rockland, 2005b). There are projections from midline thalamus to the claustrum (Vertes et al., 2006), but like almost all thalamic projections (except those from anterior dorsal thalamus to the subiculum), these can be considered as zinc-negative.

A second, indirect line of evidence is the dendritic morphology of pyramidal neurons in layer 6 (Katz, 1987; Ojima et al., 1992; Olsen et al., 2012; and reviewed in Briggs, 2010; Thomson, 2010). Corticothalamic neurons have short, thin apical dendrites typically not extending much above layer 4. At least a subset of cortical feedback projecting neurons also have short, non-tufted apical dendrites (for monkey: Lund et al., 1981; Figure 9 in Rockland, 1994; Berezovskii et al., 2012). Cortico-claustral neurons have nontufted apical dendrites ascending to layer 1 (Katz, 1987). Of these three groups, corticothalamic neurons can be assumed to be $\mathrm{Zn}-$. Cortico-cortical neurons, in monkey, are a mix of $\mathrm{Zn}+$ and $\mathrm{Zn}-$, as noted above. An interesting possibility is that some cortico-claustral neurons, which have a nontufted apical dendrite (even though this appears to ascend more superficially than cortical neurons), are $\mathrm{Zn}+$. The proportion of layer 6 neurons with long apical dendrites (i.e., putative corticoclaustral) is likely to be area and species specific. From intracellular fills, these are reported as unusually abundant_almost $40 \%$ of the filled neurons-in layer 6 of rat medial prefrontal cortex, although the projectional identity is unknown (Van Aerde and Feldmeyer, 2013).

If cortico-claustral neurons, or a subset of these, are $\mathrm{Zn}+$, we can further speculate whether individual neurons might send collaterals to cortical areas and the claustrum. There are so far no relevant data for cortico-claustal neurons, either from double retrograde tracers or intercellular labeling; and this possibility waits for future investigations.

What can we conclude about the claustrum as part of a $\mathrm{Zn}+$ associational system? One clear point is that claustral-cortical neurons are a mixed population, of $\mathrm{Zn}+$ and $\mathrm{Zn}-$ neurons, and are presumably functionally mixed as well. Less clear is the specific role or roles of zinc in the claustrum. In general, synaptic $\mathrm{Zn}$ is associated with activity-dependent plasticity (reviewed in Frederickson et al., 2005; Nakashima and Dyck, 2009). Consistent with plasticity effects, a sizeable proportion of claustralcortical synapses are perforated $(\sim 33 \%$ in cat visual cortex; da Costa et al., 2010). By comparison, $27 \%$ of amygdalocortical terminations (putatively $\mathrm{Zn}+$ but neurochemically uncharacterized) were identified as perforated in temporal cortex, 39\% in visual cortex (for monkey: Freese and Amaral, 2006), and $\sim 25 \%$ of those in orbitofrontal (identified as $\mathrm{Zn}+$ for monkey: Miyashita et al.,
2007). Perforated synapses are specifically implicated in memory-related plasticity (Calverley and Jones, 1990; Hara et al., 2012).

Alterations in the regulation of zinc release, either as protective or harmful, have been associated with epilepsy, among other neuropathological disorders (reviewed in Paoletti et al., 2009). The well-established susceptibility of the claustrum to kindling and its implication with generalized seizures may thus be related to the presence of zinc in intrinsic claustro-claustral connections and/or in the connections between the claustrum and amygdala or the claustrum and cortex. A recent study, concerned with the role of zinc homeostasis in epileptogenicity, found that epilepsyresistant rat strains had significantly lower levels of synaptic zinc as compared to epilepsy-prone strains (Flynn et al., 2007).

\section{CLAUSTRUM AS CORTICAL?}

The identification of the claustrum, as cortical or striatal, has generated considerable discussion. On developmental grounds, the claustrum has been considered (1) as a derivative of the insula, with a pallial origin; (2) as derived from the ganglionic eminence along with the basal ganglia; or (3) as having both a pallial and subpallial derivation (reviewed in Inda et al., 2009; Pirone et al., 2012). Gene expression studies show the claustrum as having pallial markers, like the amygdala but unlike striatal structures (Miyashita et al., 2005; Pirone et al., 2012); and the claustrum is consistently reported as expressing genes in common with cortical areas (Miyashita et al., 2005; Mathur et al., 2009; Watakabe et al., under review). From a somewhat different perspective, chandelier cells, a specific type of cortical interneuron, are found in both the claustrum and amygdala, but not striatum (Inda et al., 2009). From the perspective of zinc, both the claustrum and basal ganglia have moderate levels of $\mathrm{Zn}+$ terminations, at least in part of a cortical origin; but $\mathrm{Zn}+$ neurons do not occur in the striatum (Frederickson et al., 2000). The existence of $\mathrm{Zn}+$ neurons in the claustrum is consistent with a cortical association, but is a feature shared as well with the amygdala. 


\section{CLAUSTRAL FUNCTION?}

One of the ideas consistently put forth for claustral function is that it is concerned with multisensory integration (Sherk, 1986; Edelstein and Denaro, 2004; Crick and Koch, 2005). This is consistent with its pattern of widespread connectivity, although physiological recording in alert monkeys have identified distinct claustral zones comprised of unimodal, not multimodal, neurons associated with the auditory and visual modalities (Remedios et al., 2010).

Reciprocal and widespread connectivity architecture, often seen as indicating an integrative role (Tanne-Gariepy et al., 2002; Crick and Koch, 2005), is not anatomically unique to the claustrum, but applies to other structures as well; for example, the amygdala and midline thalamus. Thus, it is not yet clear that this connectivity architecture in itself is strong support for a distinctively integrative role. Continuing work in rat, in fact, has concluded that while the efferent connectivity of the claustrum might well subserve interhemispheric coordination of motor and somatosensory whisker representations, its role as an integrator of somesthetic and motor information is less likely, since there are no projections from the somatosensory whisker representation to the claustrum (Smith et al., 2012).

Worth noting is that claustral-cortical projections terminate in both layers 1 and 4, presumably from separate subpopulations, given that $\mathrm{Zn}+$ terminations are dense in layer 1 and very sparse in layer 4. Layer 1 and layer 4 terminations are also spatially dissociable to some extent in that those in layer 1 are typically widely divergent, in contrast with the more topographically organized termination systems in layer 4 . Amygdalo-cortical projections to layer 1 are widely divergent (Freese and Amaral, 2006), as are thalamo-cortical (RubioGarrido et al., 2009), and cortical feedback (Rockland, 1994). Widespread terminations in layer 1 might contribute to the generation of synchronized oscillations, another role associated with the claustrum (Smythies et al., 2012), although more data are needed specifically concerning neurons postsynaptic to claustral inputs. In particular, is there a neuron-to-neuron reciprocity with claustral projections targeting cortico-claustral neurons?

The architecture that emerges is not so much structure-to-structure reciprocity, as a wider constellation of closely interconnected networks; namely, claustral-cortex-amygdala $(\mathrm{Zn}+$ or mixed), claustral-hippocampus-amygdala $(\mathrm{Zn}+$ or mixed), claustral-reuniens-cortex $(\mathrm{Zn}-)$, possibly hippocampus-reuniensclaustrum $(\mathrm{Zn}-)$, among others.

\section{SUMMARY}

The importance of synaptic zinc for claustral connections has been largely overlooked, despite abundant evidence of $\mathrm{Zn}+$ inputs and outputs. Synaptic zinc has been associated with activity-driven plasticity; and one might propose that the functional role of zinc for the claustrum is "similar" to that of zinc as used by the basolateral amygdala and feedback cortical connections from layer 6. More immediately, a practical consequence is that the wide range of manipulations targeting $\mathrm{Zn}+$ terminations and $\mathrm{Zn}+$ neurons (reviewed in Nakashima and Dyck, 2009) offer new tools to probe claustral organization and function. Potential approaches might include comparisons across species and mouse lines, across developmental stages, or in different environmental or pathological conditions.

\section{REFERENCES}

Berezovskii, V., Born, R. T., and Nassi, J. J. (2012). Detailed morphology of feedforward and feedback neurons in area $\mathrm{V} 2$ of primate visual cortex studied with genetically modified rabies virus. Soc. Neurosci Abstr. 464.13

Briggs, F. (2010). Organizing principles of cortical layer 6. Front. Neural Circuits 4:3. doi: 10.3389/neuro.04.003.2010

Brown, C. E., and Dyck, R. H. (2004). Distribution of zincergic neurons in the mouse forebrain. J. Comp. Neurol. 479, 156-167. doi: 10.1002/cne.20308

Brown, C. E., and Dyck, R. H. (2005). Retrograde tracing of the subset of afferent connections in mouse barrel cortex provided by zincergic neurons. J. Comp. Neurol. 486, 48-60. doi: $10.1002 /$ cne. 20522

Calverley, R. K., and Jones, D. G. (1990). Contributions of dendritic spines and perforated synapses to synaptic plasticity. Brain Res. Brain Res. Rev. 15, 215-249. doi: 10.1016/0165-0173(90)90002-6

Casanovas-Aquilar, C., Reblet, C., Perez-Clausell, J., and Bueno-Lopez, J. L. (1998). Zinc-rich afferents to the rat neocortex: projections to the visual cortex traced with intracerebral selenite injections. J. Chem. Neuroanat. 15, 97-109. doi: 10.1016/S0891-0618(98)00035-0
Clasca, F., Avendano, C., Roman-Guindo, A., Llamas, A., and Reinoso-Suarez, F. (1992). Innervation from the claustrum of the frontal association and motor areas: axonal transport studies in the cat. J. Comp. Neurol. 326, 402-422. doi: $10.1002 / \mathrm{cne} .903260307$

Crick, F., and Koch, C. (2005). What is the function of the claustrum? Philos. Trans. R. Soc. Lond. B Biol. Sci. 360, 1271-1279. doi: 10.1098/rstb.2005.1661

Cunningham, M. G., Ames, H. M., Christensen, M. K., and Sorensen, J. C. (2007). Zincergic innervation of medial prefrontal cortex by basolateral projection neurons. Neuroreport 18, 531-535. doi: 10.1097/WNR.0b013e328091c212

da Costa, N. M., Fursinger, D., and Martin, K. A. C. (2010). The synaptic organization of the claustral projection to the cat's visual cortex. J. Neurosci. 30, 13166-13170. doi: 10.1523/JNEUROSCI.312210.2010

Edelstein, L. R., and Denaro, F. J. (2004). The claustrum: a historical review of its anatomy, physiology, cytochemistry and functional significance. Cell. Mol. Biol. (Noisy-le-grand) 50, 675-702.

Flynn, C., Brown, C. E., Calasso, S. L., McIntyre, D. C., Campbell Teskey, G., and Dyck, R. H. (2007). Zinergic innervation of the forebrain distinguishes epilepsy-prone from epilepsy-resistant rat strains. Neuroscience 144, 1409-1414. doi: 10.1016/j.neuroscience.2006.11.005

Frederickson, C. J., Koh, J.-Y., and Bush, A. I. (2005). The neurobiology of zinc in health and disease. Nat. Rev. Neurosci. 6, 449-462. doi: 10.1038/nrn1671

Frederickson, C. J., Suh, S. W., Silva, D., Frederickson, C. J., and Thompson, R. B. (2000). Importance of zinc in the central nervous system: the zinccontaining neuron. J. Nutr. 130, 1471S-1483S.

Freese, J. I., and Amaral, D. G. (2006). Synaptic organization of projections from the amygdala to visual cortex areas $\mathrm{TE}$ and $\mathrm{V} 1$ in the macaque monkey. J. Comp. Neurol. 496, 655-667. doi: 10.1002/cne.20945

Garrett, B., Sorensen, J. C., and Slomianka, L. (1992). Fluoro-gold tracing of zinc-containing afferent connections in the mouse visual cortices. Anat. Embryol. 156, 451-459.

Hara, Y., Rapp, P. R., and Morrison, J. H. (2012). Neuronal and morphological bases of cognitive decline in aged rhesus monkeys. Age 34, 1051-1073. doi: 10.1007/s11357-011-9278-5

Ichinohe, N., Matsushita, A., Ohta, K., and Rockland, K. S. (2010). Pathway-specific utilization of synaptic zinc in the macaque ventral visual cortical areas. Cereb. Cortex 20, 2818-2831. doi: 10.1093/cercor/bhq028

Ichinohe, N., and Rockland, K. S. (2005a). Distribution of synaptic zinc in the macaque amygdala. J. Comp. Neurol. 489, 135-147. doi: $10.1002 / \mathrm{cne} .20632$

Ichinohe, N., and Rockland, K. S. (2005b). Zincenriched amygdalo- and hippocampo-cortical connections to the inferotemporal cortices in macaque monkey. Neurosci. Res. 53, 57-68. doi: 10.1016/j.neures.2005.06.002

Inda, M. C., DeFelipe, J., and Munoz, A. (2009). Morphology and distribution of chandelier cell axon terminals in the mouse cerebral cortex and claustroamydaloid complex. Cereb. Cortex 19, 1941-1954. doi: 10.1093/cercor/bhn057 
Katz, L. C. (1987). Local circuitry of identified projection neurons in cat visual cortex brain slices. J. Neurosci. 7, 1233-1249.

Li, Z. K., Takada, M., and Hattori, T. (1986). Topographic organization and collateralization of claustrocortical projections in the rat. Brain Res. Bull. 17, 529-532. doi: 10.1016/0361-9230(86)90220-0

Lund, J. S., Hendrickson, A. E., Ogren, M. P., and Tobin, E. A. (1981). Anatomical organization of primate cortex area VII. J. Comp. Neurol. 202, 19-45. doi: $10.1002 / \mathrm{cne} .902020104$

Majak, K., Pikkarainen, M., Kemppainen, S., Jolkkonen, E., and Pitkanen, A. (2002). Projections from the amydaloid complex to the claustrum and the endopiriform nucleus: a Phaseolus vulgaris leucoagglutinin study in the rat. J. Comp. Neurol. 451, 236-246. doi: 10.1002/cne.10346

Mathur, B. N., Caprioli, R. M., and Deutsch, A. Y. (2009). Proteomic analysis illuminates a novel structural definition of the claustrum and insula. Cereb. Cortex 19, 2372-2379. doi: 10.1093/cercor/bhn253

McKenna, J. T., and Vertes, R. P. (2004). Afferent projections to nucleus reuniens of the thalamus. J. Comp. Neurol. 480, 115-142. doi: $10.1002 /$ cne.20342

Miyashita, T., Ichinohe, N., and Rockland, K. S. (2007). Differential modes of termination of amygdalothalamic and amygdalocortical projections in the monkey. J. Comp. Neurol. 502, 309-324. doi: $10.1002 /$ cne. 21304

Miyashita, T., Nishimura-Akiyoshi, S., Itohara, S., and Rockland, K. S. (2005). Strong expression of NETRIN-G2 in the monkey claustrum. Neuroscience 136, 487-496. doi: 10.1016/j.neuroscience.2005.08.025

Nakashima, A. S., and Dyck, R. H. (2009). Zinc and cortical plasticity. Brain Res. Rev. 59, 347-373. doi: 10.1016/j.brainresrev.2008.10.003

Ojima, H., Honda, C. N., and Jones, E. G. (1992). Characteristics of intracellularly injected infragranular pyramidal neurons in cat primary auditory cortex. Cereb. Cortex 2, 197-216. doi: 10.1093/cercor/2.3.197

Olsen, S. R., Bortone, D. S., Adesnik, H., and Scanziani, M. (2012). Gain control by layer six in cortical circuits of vision. Nature 483, 47-52. doi: 10.1038/nature10835

Paoletti, P., Vergnano, A. M., Barbour, B., and Casado, M. (2009). Zinc at glutamatergic synapses. Neuroscience 158, 126-136. doi: 10.1016/j.neuroscience.2008.01.061

Perez-Clausell, J. (1996). Distribution of terminal fields stained for zinc in the neocortex of the rat. J. Chem. Neuroanat. 11, 99-111. doi: 10.1016/0891-0618(96)00131-7

Pirone, A., Cozzi, B., Edelstein, L., Peruffo, A., Lenzi, C., Quilici, F., et al. (2012). Topography of Gng2and Netrin G2-expression suggests an insular origin of the human claustrum. PLoS ONE 7:e44745. doi: 10.1371/journal.pone.0044745

Remedios, R., Logothetis, N. K., and Kayser, C. (2010). Unimodal responses prevail within the multisensory claustrum. J. Neurosci. 30, 12902-12907. doi: 10.1523/JNEUROSCI.2937-10.2010

Rockland, K. S. (1994). "The organization of feedback connections from area V2 (18) to V1 (17)," in Cerebral Cortex, Vol. 10, eds A. Peters and K. Rockland (New York, NY: Plenum Press), 261-299.

Rubio-Garrido, P., Perez-de-Manzo, F., Porrero, C., Galazo, M. J., and Clasca, F. (2009). Thalamic input to distal apical dendrites in neocortical layer 1 is massive and highly convergent. Cereb. Cortex 19 , 2380-2395. doi: 10.1093/cercor/bhn259

Sensi, S. L., Paoletti, P., Bush, A. I., and Sekler, I. (2009). Zinc in the physiology and pathology of the CNS. Nat. Rev. Neurosci. 10, 780-791. doi: $10.1038 / \mathrm{nrn} 2734$

Sherk, H. (1986). "The claustrum and the cerebral cortex," in Cerebral Cortex, Vol. 5, eds E. G. Jones and A. Peters (New York, NY: Plenum Press), 467-499.

Smith, J. B., and Alloway, K. D. (2010). Functional specificity of claustrum connections in the rat: interhemispheric communication between specific parts of motor cortex. J. Neurosci. 30, 16832-16844. doi: 10.1523/JNEUROSCI.4438-10.2010

Smith, J. B., Radhakrishnan, H., and Alloway, K. D. (2012). Rat claustrum coordinates but does not integrate somatosensory and motor cortical information. J. Neurosci. 32, 8583-8588. doi: 10.1523/JNEUROSCI.1524-12.2012

Smythies, J., Edelstein, L., and Ramachandran, V. (2012). Hypotheses relating to the function of the claustrum. Front. Integr. Neurosci. 6:53. doi: 10.3389/fnint.2012.00053

Stefannacci, L., and Amaral, D. G. (2000). Topographic organization of cortical inputs to the lateral nucleus of the macaque monkey amygdala: a retrograde tracer study. J. Comp.
Neurol. 421, 52-79. doi: 10.1002/(SICI)1096-9861 (20000522)421:1<52::AID-CNE4>3.0.CO;2-O

Tanne-Gariepy, J., Boussaoud, D., and Rouiller, E. M. (2002). Projections of the claustrum to the primary motor, premotor, and prefrontal cortices in the macaque monkey. J. Comp. Neurol. 454 140-157. doi: 10.1002/cne.10425

Thomson, A. M. (2010). Neocortical layer 6, a review. Front. Neuroanat. 4:13. doi: 10.3389/fnana.2010.00013

Valente, T., Auladell, C., and Perez-Clausell, J. (2002). Postnatal development of zinc-rich terminal fields in the brain of the rat. Exp. Neurol. 174, 215-229. doi: 10.1006/exnr.2002.7876

Van Aerde, K. I., and Feldmeyer, D. (2013). Morphological and physiological characterization of pyramidal neuron subtypes in rat medial prefrontal cortex. Cereb. Cortex. doi: 10.1093/cercor/bht278. [Epub ahead of print].

Vertes, R. P., Hoover, W. B., Do Valle, A. C., Sherman, A., and Rodriguez, J. J. (2006). Efferent projections of reuniens and rhomdoid nuclei of the thalamus in the rat. J. Comp. Neurol. 499, 768-796. doi: $10.1002 / \mathrm{cne} .21135$

Witter, M. P., Room, P., Groenewegen, H. J., and Lohman, A. H. (1988). Reciprocal connections of the insular and piriform claustrum with limbic cortex: an anatomical study in the cat. Neuroscience 24, 519-539. doi: 10.1016/0306-4522(88)90347-8

Zhang, S.-J., Ye, J., Miao, C., Tsao, A., Cerniauskas, I., Ledergerber, D., et al. (2013). Optogenetic dissection of entorhinal-hippocampal functional connectivity. Science 340, 44-58. doi: 10.1126/science. 1232627

Received: 29 January 2014; accepted: 28 February 2014. published online: 18 March 2014.

Citation: Rockland KS (2014) Zinc-positive and zincnegative connections of the claustrum. Front. Syst. Neurosci. 8:37. doi: 10.3389/fnsys.2014.00037

This article was submitted to the journal Frontiers in Systems Neuroscience.

Copyright (c) 2014 Rockland. This is an open-access article distributed under the terms of the Creative Commons Attribution License (CC BY). The use, distribution or reproduction in other forums is permitted, provided the original author(s) or licensor are credited and that the original publication in this journal is cited, in accordance with accepted academic practice. No use, distribution or reproduction is permitted which does not comply with these terms. 